\title{
TRATAMENTO CIRÚRGICO DA ICTERÍCIA OBSTRUTIVA
}

\author{
SURGICAL TREATMENT OF OBSTRUCTIVE JAUNDICE
}

Julio C.U. Coelho \& Alexandre T. Freitas

Professor Titular e Coordenador da Disciplina de Cirurgia do Aparelho Digestivo'; Mestrando do Curso de Pós-Graduação em Clínica Cirúrgica ${ }^{2}$ da Universidade Federal do Paraná.

CoRRESPONDÊNCIA: Dr. Júlio C. U. Coelho - Rua Bento Viana, 1140, ap 1501 - CEP: 80240-110 - Curitiba, Paraná - Fone-fax: (041) 322-3789 e (041) 322-0214.

COELHO JCU \& FREITAS AT. Tratamento cirúrgico das icterícias obstrutivas. Medicina, Ribeirão Preto, 30: 220-233, abr./jun. 1997.

RESUMO: Os pacientes com icterícia obstrutiva devem ser avaliados e preparados adequadamente, antes da realização de procedimentos invasivos para reduzir as complicações, principalmente as infecciosas, distúrbios de coagulação sanguínea e insuficiência renal. As causas de icterícia obstrutiva são inúmeras, sendo a principal a litíase da via biliar principal. Cerca de $6-10 \%$ dos pacientes com litíase da vesícula biliar também apresentam cálculo na via biliar principal. Outras causas comuns de icterícia obstrutiva incluem obstrução maligna e estenoses benignas da via biliar principal. Hemobilia, doença de Caroli, cisto de cóledoco, divertículos duodenais e verminose das vias biliares são causas infreqüentes. O tratamento cirúrgico de todas estas condições é discutido.

UNITERmos: Colestasia. Cirurgia. Cálculos do Ducto Biliar Comum. Colangite. Trato Biliar.

\section{INTRODUÇÃO}

A obstrução da árvore biliar com incapacidade de excretar bile para o intestino causa acúmulo, na corrente sanguínea, de substâncias normalmente excretadas no intestino. Muitas delas, incluindo sais biliares, têm efeitos tóxicos. Ainda, a falta de bile, no trato intestinal, causa má absorção de gordura e vitaminas lipossolúveis. A bile estagnada pode ser colonizada por bactérias, predispondo os pacientes a complicações infecciosas locais e sistêmicas. Episódios crônicos ou recorrentes de obstrução levam a uma resposta inflamatória que evolui, tardiamente, até uma fibrose na tríade portal hepática. Os pacientes podem apresentar dano hepático, cirrose biliar e insuficiência hepática.

$\mathrm{Na}$ icterícia obstrutiva, os pacientes têm um risco particular de desenvolverem hipotensão e insuficiência renal aguda. Estas complicações têm alta morbidade e contribuem com a alta mortalidade, observada após a cirurgia para desobstrução. A manipulação do tracto biliar pode causar refluxo de toxinas e bactérias para a circulação sistêmica ou provocar episódios de colangite. Os procedimentos sobre a via biliar, se não realizados adequadamente, também podem levar a estenose biliar iatrogênica.

\section{CAUSAS DE ICTERÍCIA OBSTRUTIVA}

Nos Estados Unidos, a principal causa de icterícia obstrutiva é a litíase da via biliar principal (coledocolitíase). Entretanto as estenoses iatrogênicas do ducto biliar, obstrução maligna por colangiocarcinoma, tumores pancreáticos e periampulares e estenoses benignas do ducto biliar distal, por pancreatite crônica também são comuns. Outras causas menos comuns de obstrução incluem cisto de colédoco, cateteres biliares, coágulos devidos à hemobilia, estenoses devidas à doença de Caroli e compressões extrínsecas (Síndrome de Mirizzi) ${ }^{1}$. No Oriente, são freqüentes parasitas como o Clonorchis sinensis e o Ascaris lumbricoides, que causam obstrução do ducto biliar comum, com posterior fibrose e estenose. Os parasitas se aderem à parede do ducto para se nutrirem ${ }^{1,2}$. As principais causas de icterícia obstrutiva estão na Tabela I. 
Tabela I - Causas de icterícia obstrutiva

$\begin{array}{ll}\text { Coledocolitíase } & \text { Doença de Caroli } \\ \text { Estenoses benignas } & \text { Colangite piogênica recorrente } \\ \text { Neoplasia da vesícula biliar } & \text { Colangite esclerosante } \\ \text { Neoplasia das vias biliares } & \text { Divertículos duodenais } \\ \text { Neoplasia de pâncreas } & \text { Equinococose } \\ \text { Neoplasia da ampola de Vater } & \text { Ascaridíase } \\ \text { Síndrome de Mirizzi } & \text { Neoplasia metastática } \\ \text { Cistos de colédoco } & \text { Doença duodenal de Crohn } \\ \text { Cateteres } & \text { Linfonodos paraductais inflamados } \\ \text { Pancreatite } & \text { Hemobilia }\end{array}$

\section{IMPLICAÇÕES DA ICTERÍCIA OBSTRU- TIVA NO PREPARO PARA A CIRURGIA}

O preparo dos pacientes com icterícia obstrutiva antes de procedimentos invasivos é imperativo. Devem ser avaliados quanto à hipovolemia, com exames complementares, que incluem hemograma com contagem de plaquetas, eletrólitos, nitrogênio uréico, creatinina, TAP e KPTT. O balanço hídrico deve ser anotado, diariamente, com especial atenção ao débito urinário. Procedimentos invasivos não devem ser realizados até as alterações hidroeletrolíticas e as coagulopatias serem compensadas.

Para a correção das coagulopatias deve ser administrada vitamina $\mathrm{K}, 10 \mathrm{mg}$, via intramuscular, diariamente. Uma correção mais urgente necessita de plasma fresco, endovenoso. Nos casos avançados, com hepatopatia avançada, associada, não é possível a correção da coagulopatia somente com vitamina $\mathrm{K}$. Nestes casos, há deficiência de outros fatores de coagulação, não dependentes da vitamina $\mathrm{K}$, incluindo o fibrinogênio. Utiliza-se plasma fresco, congelado e crioprecipitado, porém os efeitos são transitórios, a não ser que a função hepática melhore.

Pacientes com obstrução crônica evoluem para deficiências vitamínicas significativas, que podem ser evitadas com um manejo adequado. A má absorção de gordura e esteatorréia pode ser evitada pela restrição da ingestão de lipídios neutros, até $40 \mathrm{~g} /$ dia, e administração de lipídios de cadeia média, que são bem absorvidos pelo intestino, na ausência de sais biliares. As deficiências vitamínicas podem ser evitadas com a administração mensal de $10 \mathrm{mg}$ de vitamina $\mathrm{K}, 100.000$ UI de vitamina A e 100.000 UI de vitamina D. Os pacientes podem, ainda, necessitar de suplementação oral de cálcio.
A correção dos déficits de volume recupera o espaço intravascular, diminui a propensão ao desenvolvimento de hipotensão, melhora o fluxo renal, mantém o débito urinário para excreção dos metabólitos hepáticos e diminui a concentração de substâncias tóxicas na circulação. Em uma análise de trezentas e cinqüenta cirurgias por icterícia obstrutiva, de trinta e sete mortes anotadas, vinte e uma ocorreram por insuficiência renal aguda ${ }^{3}$. Avaliando-se a função renal, em portadores de icterícia obstrutiva, verificou-se que o clareamento plasmático da creatinina diminuía com o aumento da bilirrubina circulante ${ }^{4}$. $O$ rim do portador de icterícia obstrutiva torna-se muito menos resistente à hipotensão. Por isso, tem sido norma em serviços de cirurgia a recomendação de atitudes de vigilância para manter a volemia normal destes pacientes, pois a hipovolemia, seguramente, resultará em dano renal. Torna-se, assim, obrigatória a avaliação da função renal no pré-operatório, nos casos de icterícia obstrutiva. Se a sepse é evitada e os déficits de volume são prontamente corrigidos, os efeitos sistêmicos da obstrução biliar são minimizados.

Os pacientes com icterícia obstrutiva têm alto risco de desenvolverem complicações infecciosas, após procedimentos invasivos no tracto biliar, devido à constante presença de bactérias na bile. Estas bactérias ganham acesso aos tecidos pré-hepáticos e periductais, quando a pressão da bile é aumentada ou quando há lesão do epitélio ductal por fios-guia, cateteres, próteses ou manipulação cirúrgica. A bile contém dois finos microorganismos em aproximadamente metade destes casos. As complicações infecciosas são minimizadas com a utilização de antibioticoprofilaxia ${ }^{5,6}$ e normalização da pressão ductal, após o procedimento. As espécies bacterianas mais comumente encontradas são 
Escherichia coli, Klebsiella, Enterococus e Proteus $^{7}$. Espécies anaeróbicas, por exemplo, Bacterioides fragilis e Clostridium perfringens, são observadas em $15 \%$ de amostras de bile, adequadamente cultivadas ${ }^{8}$.

Os antibióticos usados para a profilaxia são os mesmos utilizados para o tratamento da colangite, administrados pelo menos trinta minutos antes do procedimento. No passado, o regime de escolha era ampicilina, associada a um aminoglicosídeo, porém a resistência à Klebsiella e Enterobacter foi descrita ${ }^{9}$ e os aminoglicosídeos são nefrotóxicos. As cefalosporinas são efetivas, porém são menos ativas contra estafilococos e S. fecalis. A ampicilina é necessária para estes microorganismos. Meticilina e ureidopenicilina são mais efetivas que a associação de ampicilina a um aminoglicosídeo, porém não atuam sobre Pseudomonas aeruginosa. Em um estudo randomizado, piperacilina foi tão efetiva quanto a associação de ampicilina e tobramicina, porém foi menos nefrotóxica, tornando-se o antibiótico preferido no tratamento de pacientes com colangite e que não têm alergia a penicilina ${ }^{5}$.

A abordagem terapêutica das complicações da icterícia obstrutiva está resumida na Tabela II.

\begin{tabular}{|c|c|}
\hline Condição clínica & Abordagem terapêutica \\
\hline Coagulopatias & $\begin{array}{l}\text { Vitamina } \mathrm{K} \text {, plasma fresco, crio- } \\
\text { precipitado }\end{array}$ \\
\hline $\begin{array}{l}\text { Deficiências nutricionais } \\
\text { e má-absorção }\end{array}$ & $\begin{array}{l}\text { Lipídios neutros }(<40 \mathrm{~g} / \mathrm{d}) \text { e de } \\
\text { cadeia média, vitaminas } \mathrm{K}, \mathrm{A}, \mathrm{D} \text { e } \\
\text { cálcio VO }\end{array}$ \\
\hline Insuficiência renal & Manutenção da volemia \\
\hline $\begin{array}{l}\text { Infecções por aeróbios e } \\
\text { anaeróbios }\end{array}$ & $\begin{array}{l}\text { Profilaxia antibiótica (com pipe- } \\
\text { racilina) e descompressão ductal }\end{array}$ \\
\hline
\end{tabular}

\section{OPÇÕES TERAPÊUTICAS}

Após o estabelecimento de um diagnóstico preciso, o fluxo livre de bile deve ser reestabelecido, para se evitarem as conseqüências da oclusão biliar, incluindo episódios graves de colangite. Isto é usualmente obtido através da remoção de cálculos ou confecção de anastomoses entre o ducto biliar e o intestino. Quando estas opções não são possíveis, a drenagem do sistema biliar com cateteres biliares externos ou próteses internas são úteis para melhorar os sintomas, porém são passíveis de obstrução. A utilização de próteses expansíveis diminuiu esta incidência ${ }^{10,11}$.
Nos pacientes com colangite, resistentes ao tratamento médico ou nos que já se apresentam com choque séptico, o entendimento da patofisiologia e efeitos adversos da obstrução biliar é importante. A descompressão do ducto com diminuição da pressão intraductal pode ser fundamental para a sobrevida. Atualmente, a cirurgia de emergência é evitada, porque a descompressão pode ser obtida por outros métodos menos invasivos. Os procedimentos cirúrgicos definitivos, quando indicados, são realizados tardiamente, em condições eletivas. Após a instituição do tratamento clínico, deve ser esperada a melhora dentro de seis a doze horas, e, na maioria dos casos, a crise estará sob controle dentro de quarenta e oito a setenta e duas horas. Se este tipo de evolução não for evidente ou se o paciente se apresentar gravemente tóxico, em qualquer ponto, o ducto deve ser descomprimido, seja cirurgicamente, por esfincterotomia endoscópica, ou por cateterização trans-hepática, percutânea ${ }^{12}$ (Tabela III).

Pessa et al. ${ }^{13}$ estabeleceram a efetividade da drenagem trans-hepática percutânea, demonstrando melhora das condições clínicas em trinta e nove de quarenta e dois pacientes com colangite aguda. Dois pacientes faleceram (5\%) e complicações do procedimento ocorreram em $7 \%$ dos pacientes. Chen et al. ${ }^{14}$ mostraram uma boa resposta em $82 \%$ dos pacientes com colangite grave e submetidos a drenagem trans-hepática. Complicações do procedimento ocorreram em 21\% dos casos. Algumas delas foram significativas, como hemobilia, hemorragia intra-abdominal, hipotensão transitória, fístula biliar, pneumotórax e hemotórax, sendo que, em quatro casos, foi necessária uma laparotomia. A drenagem percutânea trans-hepática não diminuiu significativamente a mortalidade e morbidade dos procedimentos subseqüientes ${ }^{13}$. Ela é efetiva para estabilizar pacientes com colangite tóxica ${ }^{13,14}$ e pode ser benéfica nos casos que não podem ser tratados, com sucesso, pelos métodos endoscópicos.

$O$ tratamento endoscópico da obstrução biliar é efetivo e seguro, quando realizado por endoscopistas experientes. Leese et al. ${ }^{15}$ comparou a esfincterotomia endoscópica, precocemente, no curso da colangite, com o tratamento médico e com o tratamento cirúrgico. Para a esfincterotomia, a mortalidade foi de $5 \%$, consideravelmente menor que a mortalidade de $36 \%$ para o grupo de tratamento médico. Para os pacientes com tratamento cirúrgico, a mortalidade foi de 17 a $50 \%$, a taxa mais alta foi para 
pacientes com colecistectomia prévia. A esfincterotomia endoscópica, como na drenagem percutânea, estava associada a altas taxas de complicações (28\%), porém os autores definiram estas taxas como aceitáveis, se forem comparadas com 58\% de complicações do grupo de tratamento cirúrgico.

Mais recentemente, Lai et al. ${ }^{16 / 19}$, Ditzel $^{20}$ e Wortley $^{21}$ demonstraram a segurança e eficácia da drenagem nasobiliar com um cateter de 7 Fr e uma pequena papilotomia $(<0.5 \mathrm{~cm})$ no tratamento da colangite aguda. Não foram feitos esforços para a retirada de cálculos. Oitenta e dois pacientes com colangite severa foram randomizados para descompressão cirúrgica do ducto ou drenagem endoscópica, nasobiliar, seguida do tratamento definitivo ${ }^{16}$. Os pacientes com tratamento endoscópico evoluíram com menos complicações (34\% versus $66 \%$ ) e menor mortalidade ( 10 versus $32 \%$ ) do que os pacientes com tratamento cirúrgico. $O$ método de escolha para o tratamento da colangite aguda, que não responde à terapia médica, é o endoscópico ${ }^{16}$.

A descompressão cirúrgica do tracto biliar, atualmente, é reservada para pacientes que não respondem a outros procedimentos. Tabela III. Isto é devido à alta mortalidade (21 até $40 \%$ ) para pacientes com colangite aguda ${ }^{22,23,24}$. Para pacientes criticamente enfermos, a cirurgia deve ser limitada a uma coledocotomia para descompressão, retirada de cálculos, irrigação do ducto para a remoção do pus e fechamento, com introdução de um dreno em T, de Kherr. A anastomose biliodigestiva deve ser realizada em pacientes selecionados, portadores de coledocolitíase e cujas condições clínicas se estabilizaram após a abertura do ducto.

Tabela III - Opções para restaurar o fluxo biliar na colangite* $^{\star}$

- Esfincterectomia endoscópica

- Drenagem percutânea trans-hepática

- Drenagem cirúrgica

* em ordem de prioridade

\section{MANEJO CIRÚRGICO DA ICTERÍCIA OBSTRUTIVA}

As diversas abordagens cirúrgicas para as principais causas de icterícia obstrutiva são discutidas a seguir.

\subsection{LITÍASE DA VIA BILIAR PRINCIPAL (COLEDOCOLITÍASE)}

A maioria dos cálculos de colédoco têm sua origem na vesícula biliar. Todavia, os cálculos podem se formar, primariamente, na via biliar principal, mas isto exige uma anormalidade que produza estase biliar, como obstrução parcial ou dilatação significativa. Cerca de 6-10\% dos pacientes com cálculo da vesícula biliar também possuem cálculo no ducto. Inversamente, dos pacientes com cálculo no ducto, $95 \%$ também possuem cálculo na vesícula biliar ${ }^{24}$.

Aproximadamente $40 \%$ dos cálculos do canal comum são de pigmento, o que é consideravelmente maior que a prevalência de cálculos de pigmento da vesícula biliar ${ }^{12}$. A maioria dos cálculos de pigmento, provavelmente, é formada como uma consequiência da ação bacteriana, envolvendo desconjugação do diglicuronato de bilirrubina e aglomeração do pigmento sólido com bactérias, pelo glicocálix bacteriano ${ }^{25}$. É por esta razão que os cálculos primários do canal comum são sempre cálculos de pigmento, e isto também explica por que a sepse é mais comum em pacientes com cálculos de pigmento ${ }^{26}$. Os cálculos de colesterol da via biliar principal são sempre cálculos secundários, enquanto os cálculos de pigmento podem ser primários ou secundários.

\subsubsection{Tratamento via laparotomia}

Muitos pacientes com cálculos do canal comum são tratados por apresentarem uma crise de cólica biliar com uma ecografia abdominal demostrando colelitíase. Nestas circunstâncias, a laparotomia e a colecistectomia podem ser realizadas, e, se durante o procedimento houver suspeita de cálculo do canal comum, o cirurgião realizará uma colangiografia perioperatória e, se indicado, prosseguirá com a exploração da via biliar principal.

Além de remover os cálculos, o cirurgião deve realizar um procedimento de drenagem, quando o canal comum está significativamente dilatado, quando são encontrados mais de cinco cálculos, quando não podem ser removidos todos os cálculos, ou quando houver uma ou mais cirurgias prévias, por cálculos no canal comum $^{27}$. $O$ termo procedimento de drenagem inclui esfincteroplastia, coledocoduodenostomia e coledocojejunostomia em Y de Roux. Um procedimento de drenagem permitirá a eliminação de quaisquer cálculos residuais ou recorrentes para o intestino. 
Os pacientes com coledocolitíase, já submetidos a uma colecistectomia no passado, podem ser tratados eficazmente na maioria dos casos, por esfincterotomia endoscópica ${ }^{27,28}$. As contra-indicações à esfincterotomia endoscópica incluem cálculos muito grandes ( $>2 \mathrm{~cm}$ ), estenose do canal biliar proximal ao orifício ampular, gastrectomia a Billroth II e término do canal biliar em um divertículo duodenal. Ela pode ainda ser incapaz de criar drenagem adequada, quando o ducto é significativamente dilatado. $\mathrm{Na}$ presença de contra-indicações à esfincterotomia endoscópica, ou quando esta técnica falha, geralmente, são indicadas laparotomia e coledocolitotomia.

Após a exploração cirúrgica do canal biliar comum e da remoção dos cálculos, é introduzido um tubo $\mathrm{T}$ e o ducto é fechado. $\mathrm{O}$ tubo fornece um orifício para descompressão biliar, que, de outra forma, poderia causar um extravasamento de bile pela linha de sutura, e permite que sejam realizadas colangiografias no pós-operatório. $\mathrm{O}$ tubo $\mathrm{T}$ pode ser removido no consultório médico, três semanas após a cirurgia, e o trajeto entre o ducto e a parede abdominal fecha-se espontaneamente, em vinte e quatro horas. Antes da extração do tubo $\mathrm{T}$, deve ser realizado um colangiograma. Cerca de $2 \%$ dos pacientes submetidos a coledocotomia apresentam um cálculo residual diagnosticado no colangiograma pós-operatório ${ }^{29,30}$.

Existem vários métodos para remover estes cálculos retidos na via biliar principal. O mais fácil é extrair os cálculos com uma cesta passada pelo trajeto do tubo T, sob controle radiológico ou endoscópico ${ }^{12}$. O método endoscópico evita exposição a radiação e pode ser realizado no consultório, mas requer um coledocoscópio de fibras ópticas. O método radiológico é ligeiramente mais incômodo e caro. Usando-se uma ou ambas as técnicas, é possível remover aproximadamente $80 \%$ dos cálculos retidos.

Também pode ser possível dissolver cálculos retidos, se forem compostos de colesterol ${ }^{12}$. Tanto o ácido cólico quanto a monoctanoína são eficazes solventes do colesterol, embora a última seja um pouco mais potente, in vitro. Ambos os fármacos não são tóxicos e podem ser infundidos pelo tubo T. Não devem ser forçados no ducto, se este estiver obstruido, se o paciente se queixar de dor ou se surgir colangite.

A maioria dos cálculos retidos podem ser retirados por esfincterotomia transendoscópica. Entretanto, algumas vezes, pode ser apropriada uma nova cirurgia.

A formação intensa de cálculos intra-hepáticos pode representar um problema formidável. Às vezes, estes pacientes podem ser tratados por meio de repetidas extrações de cálculos, através de uma coledocojejunostomia em Y de Roux, colocada para permitir acesso percutâneo pela parede abdominal ou através de endoscopia (p.ex., com uma anastomose com o duodeno). Em alguns destes pacientes, nos quais a doença é restrita a um único lobo, está indicada lobectomia hepática ${ }^{31}$.

\subsubsection{Tratamento via laparoscopia}

A abordagem de pacientes portadores de coledocolitíase modificou-se muito nas últimas décadas. Em 1974, iniciou-se a papilomia endoscópica e sua indicação, de início restrita aos casos de alto risco cirúrgico, estendeu-se a quase todas os casos de coledocolitíase e, certamente, com especial ênfase à litíase residual. Assim sendo, com o aparecimento da colecistectomia laparoscópica, no final da década passada, a litíase da via biliar principal encaixou-se, perfeitamente, para ser abordada pelo esfíncter de Oddi.

Edward Phillips iniciou um método alternativo, por via laparoscópica, descrevendo-o como extração transcística dos cálculos coledocianos com cesta de Dormia e visualização direta do colédoco com um coledocoscópio de fibra óptica. Em 1991, iniciou-se a abordagem dos cálculos por coledocotomia, via laparoscópica. Atualmente, com o desenvolvimento destes novos métodos, é de suma importância se fazer o diagnóstico no pré ou no intra-operatório e se determinar o tipo da coledocolitíase.

Foi proposta uma classificação, em três grupos, de pacientes portadores de cálculos da via biliar principal para se determinar o tratamento ${ }^{1}$.

Coledocolitíase especial: cálculos grandes ou gigantes, panlitíase, litíase intra-hepática e litíase mais estenose da via biliar principal. Este grupo deve ser submetido a cirurgia convencional, com derivação biliodigestiva, em muitos casos ${ }^{2}$.

Coledocolitíase complicada: com pancreatite aguda e colangite aguda. O tratamento mais empregado é a drenagem endoscópica retrógrada da via biliar principal ${ }^{3}$.

Coledocolitíase simples: "poucos cálculos" (ainda não é definido quantos são "poucos"), pequenos ou médios ( $<1 \mathrm{~cm}$ de diâmetro), localizados distalmente ao cístico e não impactados na ampola de Vater. A maioria destes casos pode ser solucionada por via laparoscópica. A colangiografia laparoscópica pelo ducto cístico pode ser realizada com sucesso, durante a colecistectomia, em até $98 \%$ dos casos. 


\subsubsection{Coledocolitíase diagnosticada no intra-operatório}

\section{- Acesso via transcística}

É a via mais simples. É considerado propício para o sucesso do procedimento através desta via, nos casos de cístico largo que desemboque adequadamente no colédoco, cálculos menores do que $0,6-0,8 \mathrm{~cm}$, desde que não existam mais de dois cálculos na via biliar principal, localizados todos, distalmente, à união císticocoledociana. O ducto cístico deve ser elástico e de paredes distensíveis, porque pode haver a necessidade do uso de balões de dilatação. Os cálculos são retirados com cesta de Dormia. Lizana ${ }^{32}$ em uma série de trinta e quatro pacientes abordados desta maneira, obteve sucesso em vinte e quatro. Seis pacientes foram convertidos e quatro submetidos a papilotomia endoscópica.

\section{- Acesso via coledocotomia}

A coledocotomia supraduodenal clássica pode ser realizada via laparoscopia. Algumas condições são necessárias para esta conduta. A colangiografia deve mostrar um colédoco com diâmetro maior que $1 \mathrm{~cm}$, não mais de três ou quatro cálculos, claramente visíveis, na via biliar principal e passagem do meio de contraste ao duodeno. Anatomicamente, deve-se visualizar adequadamente o colédoco. Deve-se dispor de balões biliares ou de Fogarty, cestas de Dormia, aparelho de colangiografia e coledocoscópio flexível. A presença de cálculos encravados na papila impossibilita esta técnica, sendo necessária a conversão ou a realização de papilotomia endoscópica transoperatória. Lizana $^{32}$, em um total de vinte e dois pacientes portadores de coledocolitíase, abordados via coledocotomia laparoscópica, obteve êxito em dezoito casos. A conversão foi necessária em quatro pacientes.

\subsubsection{Coledocolitíase diagnosticada no pré-operatório}

O melhor método de tratamento de coledocolitíase simples com vesícula in situ ainda não está estabelecido. Atualmente, a maioria dos cirurgiões prefere a realização de colangiografia endoscópica, retrógrada, com papilotomia no pré-operatório, com resultados de $80 \%$ de êxito, seguindo-se, então, a colecistectomia laparoscópica. Para os $20 \%$ em que a endoscopia falha, a alternativa mais freqüente é a cirurgia clássica. Entretanto, em centros especializados, a colecistectomia, associada à exploração laparoscópica da via biliar principal, é a opção de escolha.

\subsection{ESTENOSESBENIGNASDOSDUCTOSBILIARES}

As estenoses benignas do colédoco, em 97\% dos casos, seguem-se a uma cirurgia das vias biliares, geralmente, a colecistectomia. Muitos fatores estão implicados: vesícula biliar inflamada, relações anatômicas aberrantes, drenagem prolongada com tubo em $\mathrm{T}$, colecistotomia, introdução intempestiva de sonda no ducto biliar, para remover cálculos, e tentativas de colangiografia operatória. Pequenas fístulas biliares após intervenções cirúrgicas, podem levar à formação de abscessos periductais seguido de constrição do ducto adjacente. Outras causas incluem: interferência na vascularização do ducto (transplante hepático, ressecções de neoplasias da cabeça do pâncreas), excisão de um cisto de colédoco ou de um tumor benigno, traumatismo, úlcera duodenal perfurada ou penetrante, pancreatite crônica, tumores benignos dos ductos biliares e colangite esclerosante primária.

O ducto biliar, acima da estenose, está dilatado e espessado e, abaixo, ele é representado por um cordão fibroso difícil de se identificar à cirurgia. A bile é viscosa e, geralmente, infectada, pequenos cálculos podem estar presentes. $\mathrm{O}$ fígado exibe colestase e a cirrose biliar pode se desenvolver em pouco tempo ${ }^{33}$.

$O$ tratamento pode ser realizado com dilatações, com balão ou por cirurgia. As dilatações são realizadas por via endoscópica ou percutânea. $\mathrm{Na}$ percutânea um balão é insuflado na área estenosada e, em seguida, um cateter percutâneo com numerosos orifícios, é introduzido para drenagem externa e interna simultaneamente. As dilatações podem ser repetidas ou endopróteses são posicionadas. A dilatação endoscópica, geralmente, requer papilotomia preliminar. Estenoses densas, fibrosas e longas podem não ser dilatadas e sofrer recidiva em pouco tempo ${ }^{34}$.

A cirurgia deve ser realizada o mais breve possível após a lesão original, antes que uma colangite obliterativa, formação de aderências ou alterações hepáticas secundárias aumentem o risco e as dificuldades técnicas ${ }^{33}$. Dois fatores determinam a cirurgia escolhida: a extensão da estenose e a extensão do ducto biliar disponível para o reparo. Raramente se realiza a excisão da estenose e anastomose términoterminal do ducto, devido à elevada incidência de deiscência da anastomose e fístula ${ }^{35}$.

A mortalidade peri e pós-operatória é de $13 \%$, geralmente por insuficiência hepática ou hemorragia ${ }^{36}$. 
A recidiva da estenose é freqüente, e cerca de $25 \%$ dos casos necessitam nova intervenção. Dos casos que recorrem, dois terços o fazem dentro de dois anos e $90 \%$ em até cinco anos ${ }^{37}$. Se o paciente permanecer assintomático por quatro anos após a cirurgia, há chance de $90 \%$ de cura completa.

\subsection{NEOPLASIAS PANCREÁTICAS}

Nos Estados Unidos, a neoplasia do pâncreas exócrino é a quarta causa de morte por câncer no homem e a quinta causa na mulher. $O$ adenocarcinoma ductal corresponde a cerca de 90\% dos tumores exócrinos. Somente cerca de $10 \%$ são restritos ao pâncreas, no momento do diagnóstico, $40 \%$ têm doença local avançada e 50\% doença metastática $^{38}$. Em $75 \%$ dos casos, acomete a cabeça do pâncreas, podendo causar sintomas ainda quando potencialmente curável ${ }^{38}$. A icterícia, na ausência de outros sintomas, é associada a um melhor prognóstico. O cistoadenoma e o cistoadenocarcinoma são neoplasias raras, que ocorrem mais na mulher e no idoso, têm crescimento lento, um curso insidioso, ocorrendo metástases tardiamente, e têm um prognóstico melhor $^{39}$.

A ressecção cirúrgica é recomendada somente se for considerada curativa. Para isto, deve existir ausência de metástases regionais e à distância, ausência de envolvimento de estruturas adjacentes como: veia mesentérica superior, veia porta, veia cava e artéria mesentérica superior. Cerca de $20 \%$ dos tumores da cabeça do pâncreas são ressecáveis, e somente $5 \%$ dos localizados em corpo e cauda. A ressecção curativa mais frequiente para os tumores da cabeça do pâncreas é a pancreatoduodenectomia (operação de Whiple). Inclui ressecção do estômago distal, vesícula biliar, ducto colédoco, cabeça do pâncreas, duodeno, jejuno proximal e linfáticos regionais. A restauração da continuidade do trato gastrointestinal requer uma pancreatojejunostomia, coledocojejunostomia e gastrojejunostomia. Cerca de um terço dos cirurgiões nos Estados Unidos realizam uma modificação da técnica, que compreende a preservação do piloro com o intuito de se evitarem seqüelas nutricionais. A sobrevida dos pacientes em cinco anos é de cerca de $10 \%{ }^{38}$. A pancreatectomia total foi proposta com base no fato que, em 30 a $40 \%$ dos casos, o tumor é multifocal, não podendo ser totalmente ressecado com o procedimento de Whiple. Porém estudos mais recentes não mostraram me- lhora na sobrevida e também questionam estas porcentagens elevadas. A ressecção de Whiple estendida compreende uma maior dissecção dos linfonodos regionais, com ressecção dos vasos mesentéricos superiores e veia porta, quando invadidos pelo tumor. Poucos cirurgiões optam por este procedimento devido a sua maior morbidade e ausência de eficácia comprovada.

Tardiamente, no curso da doença, a icterícia obstrutiva ocorre em $70 \%$ dos pacientes. A colecistojejunostomia e coledocojejunostomia são procedimentos paliativos seguros. A coledocojejunostomia em Y de Roux é superior à em alça, por evitar o refluxo do conteúdo intestinal para a via biliar, com conseqüente colangite. A sobrevida destes pacientes está em torno de sete a oito meses. Para pacientes com risco cirúrgico muito elevado, realiza-se introdução de próteses biliares via percutânea ou endoscópica. $O$ principal problema desta técnica é a obstrução da prótese, com recorrência da icterícia e colangite. Em cerca de dois terços dos pacientes, e necessário troca da prótese a cada dois ou três meses. O emprego de próteses auto-expansivas reduziu, mas não eliminou a obstrução da prótese.

\subsection{CARCINOMA DA VESÍCULA BILIAR}

É o tumor maligno mais freqüente das vias biliares. A litíase biliar predispõe a esta neoplasia, estando presente em $75 \%$ dos $\operatorname{casos}^{40}$. O adenocarcinoma representa mais de $80 \%$ dos casos, o restante correspondendo a carcinoma de células escamosas, adenoacatomas e outros ${ }^{41}$. O tumor, geralmente, nasce no fundo ou colo da vesícula e a sua rica drenagem venosa e linfática permite rápida propagação para linfonodos regionais, causando icterícia e disseminação. O leito hepático é invadido e há extensão local para o duodeno, estômago e cólon. Nevin ${ }^{42}$ propôs o seguinte estadiamento, de acordo com a extensão do acometimento: I. intramucosa, II. submucosa e muscular, III. serosa, IV. serosa mais linfonodos regionais, V. extensão para o fígado ou metástases à distância. A maioria dos sobreviventes a longo prazo, após a colecistectomia apresenta a doença em estágio I ou II. Infelizmente, 75\% dos pacientes possuem doença em estágio IV ou V, quando procuram tratamento médico.

Geralmente, não há suspeita do tumor no pré-operatório, a maioria dos pacientes é submetida 
à laparotomia para tratamento de colecistite, icterícia ou colangite. Na maioria dos pacientes, as metástases à distância, ou mais frequientemente, a invasão local, excluem qualquer tentativa de ressecção curativa ${ }^{41}$. Nos casos em que ocorre invasão direta dos ductos biliares, o tumor é quase sempre irressecável, sendo tratado com a inserção de próteses, através de abordagem trans-hepática ou endoscópica. Em $25 \%$ dos casos, o tumor é restrito à vesícula biliar ou a disseminação é limitada às áreas adjacentes. Nestes casos, a ressecção é passível, com chances de cura. Para a doença no estágio I, a colecistectomia isolada é suficiente (geralmente é um achado incidental). Na doença invasiva, restrita à vesícula biliar, o procedimento de escolha é a colecistectomia, ressecção de uma cunha de três a cinco cm de fígado, constituindo o leito da vesícula biliar, além de ressecção do canal cístico e dos linfonodos pericoledociais ${ }^{41}$. Esta cirurgia é indicada mesmo nos pacientes com tumores invasivos, restritos às camadas mucosas e submucosas da vesícula biliar, porque sua taxa de sobrevida em cinco anos é de apenas $65 \%$ na colecistectomia isolada. Em $25 \%$ dos casos, o diagnóstico é feito, primariamente, pelo patologista, ao examinar uma vesícula biliar removida por litíase biliar sintomática. Embora não haja prova de que a sobrevida é prolongada, é recomendada nova cirurgia, nestes casos, para ressecar o leito da vesícula biliar e os linfonodos próximos, que tendem a ser envolvidos precocemente. Cirurgias maiores, como a lobectomia hepática direita, parecem apenas aumentar os índices de mortalidade cirúrgica. A experiência com radioterapia e quimioterapia auxiliares é limitada.

A sobrevida média, após o diagnóstico, é de seis meses. Apenas 5\% dos pacientes sobrevivem cinco anos. Em quase todos estes indivíduos, o tumor é descoberto incidentalmente ${ }^{41}$.

\subsection{CARCINOMA DOS DUCTOS BILIARES}

Os carcinomas dos ductos biliares são raros e, geralmente, associados a um mau prognóstico. Um estudo com sessenta e cinco pacientes portadores desta patologia mostrou em exames de necrópsia, uma incidência de metástases de $75.4 \%$. Estes carcinomas são quatro vezes menos freqüentes que os da vesícula biliar. Geralmente, acomete pacientes na sétima década. Sua etiologia não é conhecida, mas vários fatores estão envolvidos: colite ulcerativa, colelitíase (relação menos nítida que para o carcinoma da vesícula biliar), cistos coledocianos, doença de Caroli, fígado policístico, fibrose hepática congênita, infecção pelo Clonorchis sinensis e portadores de febre tifóide. Histologicamente, costuma ser um adenocarcinoma secretor de muco, com epitélio cubóide ou colunar e estroma fibroso, abundante. Longmire $^{43}$ estabeleceu uma classificação amplamente utilizada, dividindo-se as vias biliares em três áreas: (1) região superior, incluindo ductos hepáticos direito e esquerdo, a confluência dos mesmos (tumor de Klatskin) e o ducto hepático comum (50\% dos casos); (2) região média, que se estende da junção do ducto hepático comum com o ducto cístico até o pâncreas (20\%); (3) região distal ou intrapancreática, não incluindo a ampola de Vater (20\%). Em cerca de 10\% dos casos, sua distribuição é difusa ${ }^{41}$. A invasão do ligamento hepatoduodenal ocorre, precocemente, com acometimento da artéria hepática e veia porta, causas mais freqüentes de irressecabilidade ${ }^{44}$, outras causas são a infiltração do fígado, pâncreas e metástases para lifonodos e à distância.

O tratamento curativo é cirúrgico, porém somente 15 a $20 \%$ são ressecáveis ${ }^{45,46}$. A técnica cirúrgica depende da localização e extensão do tumor, idade e condições gerais do paciente. Um tumor proximal à confluência dos ductos hepáticos direito e esquerdo pode ser ressecado, dependendo do ducto envolvido, com uma hepatectomia direita ou esquerda. Se o tumor envolve os dois ductos, a ressecção com esqueletização, com ou sem ressecção hepática central, em bloco, pode ser realizada, sendo que a via biliar é reconstruída através de uma hepaticojejunostomia em Y de Roux. Para os tumores da região média pode ser realizada uma ressecção segmentar do colédoco ou duodenopancreatectomia. Para os tumores da porção intrapancreática, a duodenopancreatectomia é a operação de escolha.

$O$ tratamento paliativo deve ser considerado, se o paciente estiver sem condições clínicas de ser submetido à cirurgia curativa ou metástases regionais ou à distância ou invasão local estiverem presentes. Pode-se realizar drenagem percutânea ou endoscópica dependendo do nível e da extensão da lesão. Uma endoprótese pode ser colocada, eliminando a drenagem externa. Os procedimentos cirúrgicos possíveis para descompressão são: a drenagem biliar através de um tubo único ou bilateral trans-hepático, drena- 
gem com tubos através da área tumoral e procedimentos de derivações intra e extra-hepáticas com uma alça intestinal. Para os tumores proximais não ressecáveis, a derivação intra-hepática com uma alça intestinal é o método preferido, que pode ser realizado por ressecção de parte do lobo hepático esquerdo ou através de dissecção intra-hepática e anastomose de uma ramo do ducto hepático principal com uma alça jejunal ${ }^{47}$. Para tumores distais irressecáveis, com ducto cístico permeável, a colecistostomia pode ser realizada como um método simples de drenagem externa. A anastomose entre o ducto biliar e o intestino pode ser realizada através de uma coledocoduodenostomia, coledocojejunostomia e hepaticojejunostomia. Estas derivações melhoram a qualidade de vida do paciente, com baixa morbidade pós-operatória, quando comparadas àquela da drenagem biliar externa e da intubação endoscópica.

\subsection{CARCINOMADA AMPOLA DE VATER}

Cerca de $10 \%$ dos tumores periampulares têm origem da ampola de Vater. A icterícia ocorre precocemente, devido a sua localização próxima ao ducto biliar, assim o diagnóstico é realizado no início da doença, com maiores taxas de ressecabilidade e melhor prognóstico do que para os outros tumores periampulares.

O tratamento consiste da pancreatoduodenectomia, com sobrevida em cinco anos de 35 a $40 \%{ }^{38}$. Ocasionalmente, em pacientes que não são candidatos à cirurgia de Whiple, a excisão local do tumor, por uma duodenotomia, é indicada.

\subsection{COLANGITE ESCLEROSANTE}

A colangite esclerosante é uma condição rara, na qual os canais biliares são envolvidos por um processo inflamatório, estenosante, de origem desconhecida. A etiologia está relacionada a um processo imune. Cerca de $70 \%$ dos pacientes manifestam o fenótipo de antígeno leucocitário humano (HLA) B8 ou DR3, marcadores genéticos, associados a várias doenças auto-imunes, específicas de vários órgãos. Cerca de $50 \%$ dos pacientes são portadores de colite ulcerativa. A patologia é composta de inflamação e fibrose dos ductos biliares que, à colangiografia, consiste de rigidez e irregularidade dos ductos, com múltiplos locais de saliências e esteno$\mathrm{se}^{12}$. A doença, geralmente, envolve tanto os ductos intra-hepáticos quanto os extra-hepáticos, porém há variantes onde ela é restrita a apenas uma destas regiões. No diagnóstico pode haver confusão com o colangiocarcinoma esclerosante, porém as alterações difusas, na colangiografia, são características de colangite esclerosante.

A doença com apresentação subclínica não exige tratamento e não tende a evoluir. Atualmente, não estão comprovados benefícios com o uso de corticóides ou agentes imunossupressores como a azatioprina ou ciclosporina. As estenoses dominantes, demonstradas por colangiografia, podem ser dilatadas por cateteres introduzidos via trans-hepática. Sondas para drenagem prolongada podem ser introduzidas via trans-hepática, endoscópica ou cirúrgica e parecem ser mais eficazes que a dilatação ${ }^{48}$. No caso de uma estenose dominante na extremidade inferior, com doença proximal leve, a sua excisão com hepaticojejunostomia é apropriada. Lillemoe; Pitt \& Cameron ${ }^{49}$ obtiveram bons resultados com ressecção da bifurcação do canal hepático, onde a doença é geralmente mais grave, e sondagem dos ductos lobares, após reconstrução por uma hepaticojejunostomia em Y de Roux. O transplante hepático é a melhor opção para doença avançada progressiva.

\subsection{COLANGITE PIOGÊNICA RECORRENTE}

Também conhecida como colangio-hepatite oriental ou colangite primária. É caracterizada por infecção crônica e formação de cálculos no canal biliar. Acomete habitantes do Sudoeste Asiático, principalmente em Formosa e no sul da China ${ }^{12}$. No Ocidente, deve ser considerada como causa de colangite, em imigrantes da Ásia.

A teoria etiológica considera a bacteremia portal como evento inicial, precedendo alterações dos ductos biliares. A E. coli pode ser cultivada em praticamente todos os casos, ela produz glucoronidase, que desconjuga a bilirrubina e produz a formação de cálculos de bilirrubinato. $\mathrm{O}$ epitélio ductal torna-se inflamado e fibrótico e, associado a cálculos e restos epiteliais, causa obstrução. A vesícula biliar está envolvida em somente $15 \%$ dos casos. Se a sepse ascender, pode sobrevir formação de abscesso intra-hepático. Cerca de metade dos pacientes são infestados por Clonorchis sinensis, contraído através da ingesta de peixe de água fresca cru. É discutível a relação etiológica entre a colangite piogênica, recorrente e a clonorquíase. É necessária colangiografia retrógrada, endoscópica ou 
trans-hepática para o diagnóstico definitivo e planejar o tratamento.

A esfincterotomia endoscópica é eficaz para pacientes com cálculos restritos aos ductos biliares que não possuem estenoses ductais, com sucesso em torno de $80 \%$ dos casos. A cirurgia é indicada no fracasso da esfincterotomia endoscópica ou na doença avançada com complicações ${ }^{50}$. $\mathrm{Na}$ ausência de estenoses, realiza-se uma coledocotomia e remoção dos cálculos, seguida por esfincteroplastia transduodenal e colecistectomia, com resultados bons, em $85 \%$ dos pacientes. Nos casos de dilatação ductal, por estenoses, ou quando a esfincteroplastia falhou anteriormente, o procedimento de escolha é a coledocojejunostomia em Y de Roux ${ }^{51}$, com resultados satisfatórios em $75 \%$ dos casos. Os sintomas persistentes são devidos à formação de cálculos intra-hepáticos recorrentes. Se houve formação de abscessos hepáticos, estes podem ser drenados. A lobectomia pode ser indicada quando um lobo se torna bastante fibrosado e cronicamente infectado e o lobo oposto é relativamente poupado.

\subsection{SIINDROME DEMIRIZZI}

Síndrome de Mirizzi é a impactação de um cálculo no ducto cístico ou colo da vesícula biliar, causando obstrução do ducto hepático comum, podendo evoluir a um quadro de colangite recorrente. Anatomicamente, o ducto cístico percorre um trajeto paralelo ao ducto hepático comum. Csendes et $\mathrm{al}^{52}$ propuseram uma classificação da síndrome em quatro tipos, baseada no grau de erosão do ducto biliar comum. No tipo 1, ocorre a impactação do cálculo que causa somente compressão extrínseca do ducto hepático comum. No tipo 2, ocorre erosão de $1 \backslash 3$ da circunferência do ducto hepático comum. No tipo 3, erosão de $2 \backslash 3$ da circunferência e, no tipo 4, ocorre destruição completa da parede do ducto. O tratamento é baseado no grau de lesão. É importante evitarem-se lesões inadvertidas ao ducto hepático comum. Na ausência de fístula, Baer ${ }^{53}$ indica uma colecistectomia parcial, deixando-se o colo da vesícula, visto que o ducto cístico está sempre ocluído por fibrose ou processo inflamatório. Quando a fístula está presente, é necessário uma coledocotomia longitudinal, diretamente sobre o cálculo, para a sua remoção. A colecistectomia é, então, realizada e o ducto cístico suturado sobre um dreno de Kherr. Algumas vezes, o fechamento da fístula é difícil, sendo necessário um "flap" da parede da vesícula para a sua conclusão. Um método alternativo proposto por Baer ${ }^{53}$ é a confecção de uma coledocoduodenostomia laterolateral ou uma anastomose em Y de Roux.

\subsection{TUMORES BENIGNOS DOS DUCTOS BILIARES EXTRA-HEPÁTICOS}

São raríssimos e costumam passar despercebidos, até que haja sinais de obstrução biliar ou colangite. A identificação, no pré-operatório, é difícil, porém importante, já que sua ressecção é curativa.

O papiloma é um tumor polipóide que se projeta para o lúmen do colédoco. É pequeno, macio, séssil ou pediculado. Às vezes, sofre transformação maligna ${ }^{54}$. O adenomioma localiza-se em qualquer parte do trato biliar, é firme e bem delimitado, seu diâmetro pode chegar até quinze $\mathrm{cm}$. O cistoadenoma apresenta-se como uma massa pediculada que se estende para dentro do colédoco. O fibroma é pequeno e firme e causa obstrução precoce dos ductos biliares ${ }^{40}$. O tumor de células granulosas é de origem mesenquimatosa, afeta mulheres jovens e negras, causando colestase. O tratamento destas lesões benignas é a ressecção local.

\subsection{CISTOS CONGÊNITOS DO COLÉDOCO}

Existem diversas variantes morfológicas da doença cística do ducto biliar extra-hepático: (1) dilatação fusiforme (95\%), (2) divertículo sacular, projetando-se da região lateral do ducto (4\%), (3) dilatação sacular da extremidade do ducto, na ampola (coledococele) $(1 \%)^{12}$. Em quase todos os pacientes, os ductos pancreático e biliar unem-se para formar um canal comum proximal à conexão com o duodeno. Acredita-se que isto é importante na etiologia, porque permite a regurgitação do suco pancreático que é enfraquecedor da parede ductal ${ }^{12}$. Em 50\% dos casos as manifestações clínicas ocorrem após os dezessete anos de idade, com dor, icterícia, colangite e, em alguns casos, uma massa em hipocôndrio direito que consiste de ductos dilatados repletos de cálculos.

O tratamento cirúrgico consiste da excisão do ducto anormal, seguida por anastomose jejunal em Y de Roux ao coto do canal hepático e 
colecistectomia $^{55}$. A colecistoduodenostomia e colecistojejunostomia são mais simples, porém menos definitivas. Elas tendem à formação de estenose gradual, muitas vezes necessitando reoperação. $\mathrm{O}$ cisto congênito do colédoco é uma lesão pré-maligna, preferindo-se assim a ressecção.

\subsection{DOENÇA DE CAROLI}

Consiste de múltiplas dilatações saculares congênitas dos ductos biliares intra-hepáticos. A maioria dos pacientes torna-se sintomática entre os vinte e cinqüenta anos, devido à formação de cálculos intra-hepáticos e colangite ou a complicações da hipertensão porta. Existem duas formas da doença de Caroli: uma que acomete apenas os ductos, e outra, mais frequiente, associada a fibrose hepática congênita e rim esponjoso, medular ${ }^{56}$.

O tratamento antimicrobiano pode controlar as crises de colangite. Procedimentos cirúrgicos podem facilitar o esvaziamento ductal ou extrair cálculos, mas a anomalia hepática não pode ser definitivamente corrigida. O lobo esquerdo, raramente, pode ser envolvido isoladamente, e a lobectomia esquerda é curativa.

\subsection{HEMOBILIA}

Clinicamente, apresenta-se com a tríade de cólica biliar, icterícia obstrutiva e sangramento intestinal oculto ou grosseiro. É conseqüência de traumas hepáticos (causa mais freqüente), biópsia hepática, colangiografia trans-hepática, neoplasia biliar ou hepática, abscesso hepático ou cálculo biliar ${ }^{12}$. A passagem de sangue para o sistema biliar resulta de uma fístula arteriobiliar. Quando o sangramento é vultoso, o sangue se deposita nas porções mais inferiores da via biliar, formando coágulos que causam a cólica e icterícia obstrutiva ${ }^{57}$.

Se o sangramento não for intenso, o tratamento inicial é expectante. A hemorragia pode cessar espontaneamente, caso não ocorra, está indicada a embolização arterial seletiva do local do sangramento ${ }^{57}$.

Nos casos sem resposta, está indicado o tratamento cirúrgico, que inclui desbridamento com hemostasia, hepatectomia e ligadura do ramo direito ou esquerdo da artéria hepática. As ressecções hepáticas de emergência cursam com alta mor- bidade e mortalidade, sendo restritas aos casos de trauma com desvitalização de tecido hepático ${ }^{58}$.

\subsection{OUTRAS CAUSAS}

Os divertículos duodenais podem obstruir o canal comum por distorção anatômica de sua entrada duodenal, por diverticulite ou por um enterólito no saco. A coledocoduodenostomia ou a coledocojejunostomia em Y de Roux é tratamento mais simples que tentar excisar o divertículo ou aumentar cirurgicamente sua entrada no duodeno ${ }^{59}$.

A equinococose, por rotura de um cisto no ducto, pode causar cólica biliar, icterícia e colangite. $\mathrm{O}$ tratamento é a remoção cirúrgica dos restos da hidátide obstrutiva e cistos-filhos do ducto, e excisão do cisto-mãe do fígado. A injeção de formol não é mais usada, porque pode causar lesão dos ductos biliares, em pacientes com comunicação biliar. $\mathrm{O}$ mebendazol ou albendazol podem ser administrados em associação com a cirurgia, para ajudar a minimizar a possibilidade de implantação peritoneal do parasita ${ }^{12}$.

$\mathrm{Na}$ ascaridíase, os vermes podem invadir o ducto biliar pelo esfíncter de Oddi, a partir do duodeno, causando cólica, icterícia e dor no hipocôndrio direito ${ }^{12}$. Geralmente, apenas um verme invade o canal biliar, mas, em casos extremos, pode haver vários. As complicações consistem de estenose do canal biliar, cálculos, perfuração, colecistite aguda e formação de abscesso hepático. Pode-se tentar a retirada com endoscopia associada a antimicrobianos e piperazina ${ }^{12}$. Se a obstrução permanecer, ou na vigência de complicações, é indicada a laparotomia com exploração do canal comum e retirada dos parasitas.

O câncer metastático é uma causa eventual de obstrução do canal biliar. Os tumores primários, responsáveis com maior freqüência são o adenocarcinoma do cólon (dois terços dos casos), vesícula biliar, pâncreas, intestino delgado, estômago, mama, ovário, melanoma e linfoma ${ }^{12}$. É indicada uma descompressão cirúrgica com uma alça em Y de Roux. Se a descompressão cirúrgica não for possível, é necessária intubação trans-hepática permanente. Os linfomas respondem tão rapidamente à radioterapia que a intervenção cirúrgica ou radiológica é desnecessária.

A Tabela IV resume a estratégia cirúrgica utilizada para o tratamento das principais doenças que provocam icterícia obstrutiva. 
Tabela IV - Estratégias de tratamento de icterícia obstrutiva

\begin{tabular}{|c|c|c|}
\hline Doença & Tipo de Cirurgia & Indicações e Observações \\
\hline \multirow[t]{5}{*}{ Coledocolitíase } & Colecistectomia por laparotomia & Cólica biliar mais US anormal \\
\hline & Procedimento de drenagem & $\begin{array}{l}\text { Cirurgias prévias por coledocolitíase; } \\
\text { dilatação do canal comum; }>5 \text { cálculos ou } \\
\text { impossibilidade de removê-los }\end{array}$ \\
\hline & Esfincterectomia endoscópica & Colecistectomia prévia \\
\hline & Colecistectomia laparoscópica & Procedimento de escolha \\
\hline & Coledocotomia laparoscópica & $\begin{array}{l}\text { Coledocolitíase diagnosticada no in- } \\
\text { tra- operatório }\end{array}$ \\
\hline \multirow[t]{3}{*}{ Estenose benigna dos ductos biliares } & Dilatação percutânea com balão & $\begin{array}{l}\text { Podem ser repetidas ou colocadas en- } \\
\text { dopróteses }\end{array}$ \\
\hline & Dilatação endoscópica & Requer papilotomia preliminar \\
\hline & $\begin{array}{l}\text { Excisão de estenose e anastomose do } \\
\text { ducto biliar }\end{array}$ & Alta incidência de deiscência e fístula \\
\hline \multirow[t]{2}{*}{ Neoplasias pancreáticas } & $\begin{array}{l}\text { Ressecção cirúrgica } \\
\text { (pancreatoduodenectomia) }\end{array}$ & $\begin{array}{l}\text { Somente se curativa (10\%) } \\
\text { (ausência de invasão local e de metás- } \\
\text { tases) }\end{array}$ \\
\hline & $\begin{array}{l}\text { Colecistojejunostomia e coledocojeju- } \\
\text { nostomia }\end{array}$ & Paliativo (90\%) \\
\hline \multirow[t]{2}{*}{ Carcinoma da vesícula biliar } & $\begin{array}{l}\text { Colecistectomia com ressecção em cu- } \\
\text { nha do leito hepático da vesícula biliar, } \\
\text { do ducto cístico e dos linfonodos perico- } \\
\text { ledociais }\end{array}$ & Neoplasia restrita à vesícula biliar (25\%) \\
\hline & $\begin{array}{l}\text { Inserção de próteses por abordagens } \\
\text { endoscópica ou trans-hepática }\end{array}$ & Invasão dos ductos biliares (75\%) \\
\hline \multirow[t]{2}{*}{ Carcinoma dos ductos biliares } & Diversos tipos de ressecção & Curativa somente em $15-20 \%$ dos casos \\
\hline & Drenagem percutânea ou endoscópica & Paliativo \\
\hline Carcinoma de ampola de Vater & Pancreatoduodenectomia & Sobrevida de $35-40 \%$ \\
\hline \multirow[t]{3}{*}{ Colangite esclerosante } & $\begin{array}{l}\text { Dilatação ou drenagem trans-hepática, } \\
\text { endoscópica ou cirúrgica }\end{array}$ & $\begin{array}{l}\text { Estenoses dominantes demonstradas } \\
\text { por colangiografia }\end{array}$ \\
\hline & Hepaticojejunostomia em Y de Roux & Estenose distal \\
\hline & Transplante hepático & Doença avançada \\
\hline \multirow[t]{2}{*}{ Colangite piogênica recorrente } & Esfincterectomia endoscópica & $\begin{array}{l}\text { Cálculos restritos aos ductos biliares } \\
\text { com estenose }\end{array}$ \\
\hline & Coledocojejunostomia em Y de Roux & $\begin{array}{l}\text { Dilatação ductal por estenose ou falha } \\
\text { da esfincteroplastia }\end{array}$ \\
\hline \multirow[t]{2}{*}{ Síndrome de Mirizzi } & Colecistectomia parcial & Sem fístula \\
\hline & $\begin{array}{l}\text { Colecistectomia longitudinal mais cole- } \\
\text { cistectomia }\end{array}$ & Com fístula \\
\hline Cistos congênitos do colédoco & $\begin{array}{l}\text { Excisão do ducto anormal, anastomose } \\
\text { hepático-jejunal e colecistectomia }\end{array}$ & Lesão pré-maligna \\
\hline \multirow[t]{2}{*}{ Hemobilia } & Embolização arterial seletiva local & Se não cessar espontaneamente \\
\hline & $\begin{array}{l}\text { Desbridamento, hepatectomia e ligadura } \\
\text { do ramo da artéria hepática acometida }\end{array}$ & Sangramento intenso ou refratário \\
\hline Equinococose & $\begin{array}{l}\text { Remoção cirúrgica dos cistos (do ducto } \\
\text { e do fígado) }\end{array}$ & Formol é contra-indicado \\
\hline Ascaridíase & $\begin{array}{l}\text { Retirada dos parasitas por via endos- } \\
\text { cópica ou cirúrgica }\end{array}$ & Geralmente verme único \\
\hline Metástases para o canal biliar & $\begin{array}{l}\text { Descompressão cirúrgica ou intubação } \\
\text { trans-hepática }\end{array}$ & $\begin{array}{l}\text { Nos linfomas os ductos podem ser de- } \\
\text { sobstruidos só com radioterapia }\end{array}$ \\
\hline
\end{tabular}


COELHO JCU \& FREITAS AT. Surgical treatment of obstructive jaundice. Medicina, Ribeirão Preto, 30: 220-233, apr./june 1997.

ABSTRACT: Patients with obstructive jaundice must be completely evaluated and prepared before any invasive procedure be performed in order to reduce complications, mainly infection, blood coagulation disorders and renal failure. There are several causes of obstructive jaundice and the main cause is choledocholithiais. About $6-10 \%$ of the patients with stones of the gallbladder also have choledocholithiasis. Other common causes of obstructive jaundice include malignant and benign stricture of the common bile duct. Hemobilia, Caroli's disease, cyst of choledocus, duodenal diverticuli and worms of the biliary tract are infrequent causes. Surgical treatment of all these conditions is discussed.

UNITERMS: Cholestasis. Surgery. Common Bile Duct Calculi. Cholangitis. Biliary Tract.

\section{REFERÊNCIAS BIBLIOGRÁFICAS}

1 - SINANAN MN. Acute colangitis. Infect Dis Clin North Am 6: 571-599, 1992.

2 - LIPSETT PA \& PITT HA. Acute colangitis. Surg Clin North Am 70: 1297-1312, 1990

3 - WILLIAMS RD et al. The effect of hypotension in obstructive jaundice. Arch Surg 81: 334-341, 1960

4 - DAWSON JL.Post operative renal function in obstructive jaundice: effects of a manitol diuresis. Br Med J 1: 82-86, 1965.

5 - THOMPSON JE et al. Broad spectrum penicillin as an adequate therapy for acute cholangitis. Surg Gynecol Obstet 171: 275-282, 1990.

6 - GERECHT WB et al. Prospective randomized comparison of mezlocillin therapy alone with combined ampicillin and gentamycin therapy for patients with cholangitis. Arch Intern Med 149: 1279-1284, 1989.

7 - BOEY JH \& WAY LW. Acute cholangitis. Ann Surg 191: 264-270, 1980

8 - BOURGAULT AM et al. Clinical characteristics of anaerobic bactibilia. Arch Intern Med, 139: 1346-1349, 1979

9 - KEIGHLEY MRB et al. Multivariate analysis of clinical and operative findings associated with biliary sepsis. $\mathbf{B r} \mathbf{J}$ Surg 63: $528-531,1976$

10 - TSANG T et al. Percutaneous-endoscopic biliary stent placement. Ann Intern Med 106: 389-392, 1987.

11 - HUIBREGTSE $\mathrm{K}$ et al. Biliary stent oclusion - a problem solved with self-expanding metal stents? Endoscopy 24: 391-394, 1992

12 - WAY LW \& SLEISENGER MH. Obstrução biliar, colangite e coledocolitíase. In: SLEISENGER MH \& FORDTRAN JS. Doenças gastrointestinais. Fisiopatologia, diagnóstico e tratamento, 4 ed, Guanabara Koogan, Rio de Janeiro, p. 1440-1451, 1991
13 - PESSA ME; HAWKINS IF \& VOGEL SB. The treatment of acute cholangitis: percutaneous transhepatic biliary drainage before definitive therapy. Ann Surg 4: 389-392, 1987.

14 - CHEN M; JAN Y \& LEE T. Percutaneous transhepatic biliary drainage for acute cholangitis. Int Surg 72: 131-133, 1987.

15 - LEESE T; NEOPTOLOMENOS JP \& CARR-LOCKE DL. SUCcesses, failures, early complications and their management following endoscopic sphincterotomy: results in 394 consecutive patients from a single center. Br J Surg 72: 215-219, 1985.

16 - LAI ECS et al. Endoscopic biliary drainage for severe acute cholangitis. N Engl J Med 10: 519-523, 1970

17 - LAI ECS. Acute cholangitis-endoscopic drainage or emergency surgery? Gastroenterology 99: 1530-1531, 1990.

18 - LAI ECS et al. Severe acute cholangitis: the role of emergency nasobiliary drainage. Surgery 107: 268-272, 1989.

19 - LAI ECS et al. Urgent biliary descompression after endoscopic retrograde cholangiopancreatography. Am J Surg 157: 121-125, 1989.

20 - DITZEL H \& SCHAFFALITZKY M. Endoscopic sphincterotomy in acute cholangitis due to choledocolitiasis. Hepatogastroenterology 37: 204-207, 1990.

21 - WORTLEY CS \& TOULLIJ. Endoscopic decompression for acute cholangitis due to stones. Aust N Z J Surg 60: 365-369, 1990.

22 - WELCH JP \& DONALDSON GA. The urgency of diagnosis and surgical treatment of accute supurative cholangitis. Am J Surg, 131: 527-532, 1976.

23 - LAI ECS, et al. Emergency surgery for severe acute cholangitis: the high-risc patient. Ann Surg 211: 55-59, 1989.

24 - THOMPSON JE; TOMPKINS RK \& LONGMIRE WP JR. Factors in management of acute cholangitis. Ann Surg 195: 137-145, 1982.

25 - STEWART L et al. Pigment gallstones form as a composite of bacterial microcolonies and pigment solids. Ann Surg 206: 242-250, 1987. 
26 - BERNHOFT RA et al. Composition and morphologic and clinical features of common duct stones. Am J Surg 148: 77-85,1984.

27 - ALLEN B; SHAPIRO H \& WAY LW. Management of recurrent and residual common duct stones. Am J Surg 142: 41-47, 1981.

28 - SIEGEL JH. Endoscopic papillotomy in the treatment of biliary tract disease. 258 procedures and results. Dig Dis Sci 26:1057-1064, 1981.

29 - WAY LW; ADMIRAND WH \& DUNPHY JE. Management of choledocolithiasis. Ann Surg 176: 347-359, 1972.

30 - BIRKETT DH \& WILLIAMS LF. Prevention and management of retained bile duct stones. Surg Clin North Am 61: 939-950, 1981.

31 - ADSON MA \& NAGORNEY DW. Hepatic resection for intrahepatic ductal stones.Arch Surg, 117: 611-616 1982.

32 - LIZANA C \& SEPÚLVEDA A. Tratamento laparoscópico da coledocolitíase. In: LIMA LP. Condutas em cirurgia biliopancreática, Medsi Editora Médica e Científica, Rio de Janeiro, p. 181-189, 1995

33 - SHERLOCK S. Estenoses benignas dos ductos biliares. In: Doenças do fígado e sistema biliar, 8 ed, Guanabara Koogan, Rio de Janeiro, p. 497-501, 1991.

34 - FOUTCH PG \& SIVAK Jr. MG. Therapeutic endoscopic ballon dilatation of the extrahepatic biliary ducts. Am $\mathbf{J}$ Gastroenterol 80: 575-580, 1985.

35 - PITT HA et al. Factors influencing outcome in patients with postoperative biliary strictures. Am J Surg 144: 14-21, 1982.

36 - WARREN KW \& JEFFERSON MF. Prevention and repair of strictures of the extra-hepatic bile ducts. Surg Clin North Am 53: 1169-1190, 1973.

37 - PELLEGRINI CA; THOMAS MJ \& WAY LW. Recurrent biliary stricture. Patterns of recurrence and outcome of surgical therapy. Am J Surg 147: 175-180, 1984.

38 - REBER HA. Tumors of the pancreas. In: SCHWARTZ S \&, SHIRES GT. Principles of surgery. 6th ed, McGraw-Hill, New York, p. 1421-1425, 1994.

39 - ALLEMA JH; GOUMA DJ \& OBERTOP H. Tumores exócrinos do pâncreas. In: COELHO J. Aparelho digestivo. clínica e cirurgia. 2 ed, Medsi Editora Médica e Científica, Rio de Janeiro, p.1489-1499, 1996.

40 - SHERLOCK S. Tumores da vesícula biliar e ductos biliares. In: Doenças do fígado e sistema biliar, 8 ed, Guanabara Koogan, Rio de Janeiro, p. 508-513, 1991.

41 - WAY LW. Neoplasias da vesícula biliar e canais biliares. In: SLEISENGER MH \& FORDTRAN JS. Doenças gastrointestinais. Fisiopatologia, diagnóstico e tratamento, 4 ed, Guanabara Koogan, Rio de Janeiro, p. 1456-1461, 1991.
42 - NEVIN JE et al. Carcinoma of the gallbladder. Staging, treatment, and prognosis. Cancer 37: 141-148, 1976.

43 - LONGMIRE WP et al. Carcinoma of the extrahepatic biliary tract. Ann Surg 178: 333-345, 1973.

44 - GREAGER JA \& CHAO TC. Tumores das vias biliares extra-hepáticas. In: COELHO J. Aparelho digestivo. Clínica e cirurgia. 2 ed, Medsi, Editora Médica e Científica, Rio de Janeiro, p. 1377-1387, 1996.

45 - EVANDER A et al. Evaluation of aggressive surgery for carcinoma of the extrahepatic bile ducts. Ann Surg 191:23-29, 1980.

46 - NAKAYAMA F; MIYAZAKI K \& NAGAFUCHI K. Radical Surgery for middle and distal thirds bile duct cancer. World J Surg 12: 60-63, 1988.

47 - LONGMIRE WP \& SANDFORD MC. Intrahepatic cholangiojejunostomy with parcial hepatectomy for biliary obstruction. Surgery 24: 264-276, 1948.

48 - WOOD RAB \& CUSCHIERI A. Is scerosing cholangitis complicating ulcerative colitis a reversible condition? Lancet 2: 716-718, 1980.

49 - LILLEMOE KD; PITT HA \& CAMERON JL. Sclerosing cholangitis. Adv Surg 21: 65-92, 1987.

50 - LAU WY et al. Surgical management of strictures of the major bile ducts in recurrent pyogenic cholangitis. Br J Surg 74: 1100-1112, 1987.

51 - CHOI TK; WONG W \& ONG GB. Choledochojejunostomy in the treatment of primary cholangitis. Surg Gynecol Obstet, 155: 43-45, 1982.

52 - CSENDES A et al. Mirizzi syndrome and cholecistobiliary fistula: A unifying classification. Br J Surg 77: 743-745, 1990.

53 - BAER HH et al. Management of the Mirizzi syndrome and the surgical implications of cholecistocholedocal fistula. Br J Surg 76: 633-636, 1989.

54 - NEUMANN RD et al. Adenocarcinoma in biliary papillomatosis. Gastroenterology 70: 779-782, 1976.

55 - DEZIEL DJ et al. Management of bile duct cysts in adults. Arch Surg 121: 410-415, 1986.

56 - SKUMMERFIELD JA et al. Hepatobiliary fibropolycystic diseases. A clinical and histological review of 51 patients. J Hepatol 2: 141-156, 1983.

57 - ARRUDA PCL. Hemobilia. In: COELHO J. Aparelho digestivo. Clínica e cirurgia. 2 ed, Medsi, Editora Médica e Científica, Rio de Janeiro, p. 1369-1371, 1996.

58 - CURET P et al. Hepatic hemobilia of traumatic or iatrogenic origin: recent advances in diagnosis and therapy. Review of literature from 1976 to 1981 . World J Surg 8: 2-8, 1984.

59 - McSHERRY CK \& GLEEN F. Biliary tract obstruction and duodenal diverticula. Surg Gynecol Obstet 130: 829-836, 1970. 